AperTO - Archivio Istituzionale Open Access dell'Università di Torino

Stimulation of laccases from Trametes pubescens: Use in dye decolorization and cotton bleaching

This is a pre print version of the following article:

Original Citation:

Availability:

This version is available http://hdl.handle.net/2318/1573167

since 2017-07-03T18:14:33Z

Published version:

DOI:http://dx.doi.org/10.1080/10826068.2015.1128445

Terms of use:

Open Access

Anyone can freely access the full text of works made available as "Open Access". Works made available under a Creative Commons license can be used according to the terms and conditions of said license. Use of all other works requires consent of the right holder (author or publisher) if not exempted from copyright protection by the applicable law. 
This is the author's final version of the contribution published as:

Federica Spina; Charles Junghanns; Ilaria Donelli; Rakesh Nair; Philippe Demarche; Alice Romagnolo; Giuliano Freddi; Spiros N. Agathos; Giovanna Cristina Varese. Stimulation of laccases from Trametes pubescens: Use in dye decolorization and cotton bleaching. PREPARATIVE BIOCHEMISTRY \& BIOTECHNOLOGY. None pp: 1-36.

DOI: http://dx.doi.org/10.1080/10826068.2015.1128445

When citing, please refer to the published version.

Link to this full text:

http://hdl.handle.net/2318/1573167 


\section{Stimulation of laccases from Trametes pubescens: use in dye decolorization and cotton bleaching}

Fungal laccases for application in textile industry

Federica Spina ${ }^{1}$, Charles Junghanns ${ }^{2}{ }^{1}$, Ilaria Donelli ${ }^{3}$, Rakesh Nair $^{2}{ }^{2}$ Philippe Demarche $^{2}$, Alice Romagnolo ${ }^{1}$, Giuliano Freddi $^{3}$, Spiros N. Agathos ${ }^{2}$, Giovanna Cristina Varese ${ }^{1}$

${ }^{1}$ University of Turin, Department of Life Sciences and Systems Biology, Viale P.A. Mattioli 25, 10125, Torino, Italy

${ }^{2}$ Université Catholique de Louvain, Earth and Life Institute, Place Croix du Sud 2/19, 1348 Louvain-la-Neuve,

Belgium

${ }^{3}$ Innovhub-SSI, Divisione Stazione Sperimentale per la Seta, Via G. Colombo 83, 20133, Milano, Italy

Corresponding author:

Giovanna Cristina Varese, $\mathrm{PhD}$

Mycotheca Universitatis Taurinensis, Department of Life Sciences and Systems Biology, University of Turin

Viale P.A. Mattioli 25, 10125 Turin, Italy

E-mail address: cristina.varese@unito.it

Telephone: +390116705984 Fax: +390116705962

\section{Acknowledgement}

The authors are grateful to Fondazione CRT (Turin, Italy) for the support provided to the project.

\footnotetext{
${ }^{1}$ Present address: Helmholtz-Zentrum für Umweltforschung, Centre Development and Scientific Controlling, Permoserstraße 15, 04318, Leipzig, Sachsen, Germany

${ }^{2}$ Present address: Bio Base Europe Pilot Plant, Rodenhuizekaai 1, 9042 Gent, Belgium
} 


\section{Introduction:}

The transformation of organic compounds is a sector under constant development with major technical and economic repercussions on several biotechnological fields, such as textile finishing, industrial and urban wastewater biotreatment, pulp delignification, etc. (1). However, the worldwide massive use of chemicals raises serious concerns about their environmental impact, calling for alternative eco-friendly approaches, involving microorganisms and their active enzymes.

Laccases (E.C. 1.10.3.2) are glycosylated multi-copper oxidases, able to couple the oxidation of a broad range of organic compounds to the reduction a molecule of oxygen to water. They are identified as optimal green biocatalysts, avoiding any concern about the required co-factors and the formed end-products: they work with air and produce water as the only by-product (1). Additionally, the triggered oxidative cascade can be propagated by mediators, overcoming the low redox potential $(0.4-0.8 \mathrm{mV})$ and enlarging the substrate spectrum (1). Despite these interesting capabilities, the applicability of laccases as biocatalysts is strongly dependent on the availability of significant quantities of enzymes at an affordable price.

The main sources of laccases are filamentous fungi, especially Basidiomycota, where they are involved in delignification, pathogenicity, detoxification, pigment production, etc. (1). Trametes species are generally good laccase producers, able to transform several xenobiotics (2-4).

Laccases are secreted during secondary metabolism, and several factors may stimulate their production. Media composition (carbon and nitrogen sources and concentration) and the presence of copper usually have a predominant role, even though the amplitude of the effect strongly depends on the inherent variability among fungal producers with respect to their specific physiological, genetic and ecological peculiarities (1). The C/N ratio plays an important role in secondary metabolism: in some cases, a N-rich medium is required for laccase overproduction even if some strains need N-limited conditions (5). Copper is essential for the proper folding of the laccase protein and its active sites, but it also acts directly on the promoter, influencing the transcription of the laccase gene itself (6). Besides, $\mathrm{Cu}$ interferes also with the protease activity in the culture media, protecting laccases from enzymatic degradation (7). In addition, the role of various aromatic compounds structurally related to lignin has been thoroughly investigated: some model substances as veratryl alcohol, ferulic acid and dyes strongly stimulate the enzymatic production $(6,8)$. However, taking into account that all those factors may act in a synergistic way, the a priori definition of the most powerful inducer on a certain strain is difficult to define. 
Given this complex background, the analysis of one parameter at a time would require much effort and time.

Thanks to recent developments in biostatistical tools, the cultivation process has been successfully optimized by means of central composite designs based on response surface methodology (8). This approach is able to evaluate the effects of several factors, underlying potential combinatorial interaction and identifying their optimum.

The aim of this study was to stimulate the laccases production of a Trametes pubescens strain, which was selected for its capability to decolorize and detoxify real industrial wastewaters (9). Interestingly, this strain sharply increased its laccase production as soon as the textile wastewaters treatment started (9). Hence, in addition to conventional elicitors $(\mathrm{N}$ and $\mathrm{Cu}$ ), the role of aromatic inducers was evaluated, focusing the attention on textile dyes. Furthermore, the physico-chemical properties ( $\mathrm{pH}$ and $\mathrm{T}$ optimum and stability) of the produced laccases were assessed as well as their actual biotechnological potential in the textile industry (dye decolorization and cotton fiber bleaching).

\section{Materials and Methods}

\subsection{Chemicals}

Bactopeptone was obtained from Difco while Town End (Leeds, UK) provided Acid Blue 62 and Acid Black 194. All the other chemicals were purchased from Sigma-Aldrich.

\subsection{Organism and Liquid Cultures}

Trametes pubescens MUT 2400 is preserved at the Mycotheca Universitatis Taurinensis (MUT, University of Torino, Italy). The liquid cultures were carried out in $100 \mathrm{ml}$ Erlenmeyer flasks, incubated at $30{ }^{\circ} \mathrm{C}$ and $120 \mathrm{rpm}$ in the dark in an orbital shaker. The culture medium was the same of the one published by (10). Each flask was inoculated with $0.5 \mathrm{ml}$ fungal suspension, prepared by homogenizing agar squares $\left(1 \mathrm{~cm}^{2}\right)$ derived from the margins of an overgrown colony together with sterile medium using an Ultraturrax homogenizer (IKA, Staufen, Germany).

After two days of growth the inducers were added and each trial was performed in triplicate. Stock solutions were prepared, filter-sterilized $(0.2 \mu \mathrm{m}$ syringe filters $)$ and inoculated in order to have $1 \mathrm{mM}$ veratryl alcohol (VA), 300 mg/l Acid Blue 62 (AB62) and 300 mg/l Reactive Blue 19 (RB19) as final working concentrations. Copper $\left(\mathrm{Cu}, 1 \mathrm{mM} \mathrm{CuSO}_{4}\right)$ was added alone or in combination with the other compounds. Whenever indicated, the inducers were used at different concentrations. During the 24-day cultivation, a liquid sample (300 $\mu$ l) was daily collected for analysis. 
Fermentation on larger scale $(0.351$ and 81$)$ was carried out in $500 \mathrm{ml}$ flasks and in a 101 stirrer tank reactor (Biostat ${ }^{\circledR}$ B, Sartorius), under the conditions defined by the central composite design experiment and the further RB19 concentration optimization (C/N 2.65, Cu $1.2 \mathrm{mM}, \mathrm{RB} 192.0 \mathrm{mM})$. The bioreactor was equipped with a $\mathrm{pH}$ and an $\mathrm{O}_{2}$ probe. The aeration and the agitation rate were maintained at $0.25 \mathrm{vvm}$ and $50 \mathrm{rpm}$ for the first two days and later increased to $0.375 \mathrm{vvm}$ and $75 \mathrm{rpm}$, respectively. The flasks were incubated at $120 \mathrm{rpm}$ in the dark. For the inoculum, liquid cultures were grown in $500 \mathrm{ml}$ flasks, using the above-described medium and after 7 days, the pellets were homogenized using the Ultraturrax device. The same batch was used to inoculate both the flasks and the bioreactor at $10 \%$ of the final working volume.

\subsection{Experimental Design}

To evaluate the effects of several parameters on laccase production by T. pubescens MUT 2400, a central composite experimental design (CCD) with three factors was carried out and the results were analyzed by means of response surface methodology. Copper $\left(X_{1}: 0.1-1.2 \mathrm{mM}\right), \mathrm{RB} 19\left(X_{2}: 125-480 \mathrm{mg} / \mathrm{l}\right)$ and bactopeptone $\left(X_{3}\right.$ : 16.7-50 g/l; C/N ratio 1-3) were chosen as the independent variables. The laccase activity $\left(Y_{1}\right)$ and the spacetime yield $\left(Y_{2}\right)$, in terms of the maximum activity divided by the elapsed time (day), were taken as response variables. As described in Table 1, each of the independent variables was studied at three levels and all the experiments were carried out in triplicate.

The responses $\left(Y_{\mathrm{i}}\right)$ were predicted by means of a quadratic model equation:

(Eq. 1) $Y_{\mathrm{i}}=\beta_{0}+\beta_{1} X_{1}+\beta_{2} X_{2}+\beta_{3} X_{3}+\beta_{4}\left(X_{1} X_{2}\right)+\beta_{5}\left(X_{1} X_{3}\right)+\beta_{6}\left(X_{2} X_{3}\right)+\beta_{7}\left(X_{1}\right)^{2}+\beta_{8}\left(X_{2}\right)^{2}+\beta_{9}\left(X_{3}\right)^{2}$

The experimental design, the statistical analyses and the mathematical modeling were obtained by means of JMP ${ }^{\circledR}$ 8.0.1 (SAS Institute Inc., NC, USA).

\subsection{Enzymatic characterization}

The culture broth collected at the production peak was filtered using $0.2 \mu \mathrm{m}$ paper filter, buffered with sodiumphosphate buffer $0.1 \mathrm{M} \mathrm{pH} 7$ and then maintained at $4{ }^{\circ} \mathrm{C}$.

The effect of $\mathrm{pH}$ was evaluated in terms of stability (half-life, $\mathrm{t}_{1 / 2}$ ) and optimum, using Britton-Robison buffer $0.1 \mathrm{M}$ (pH range 2-8) at $25^{\circ} \mathrm{C}$. The optimal $\mathrm{pH}$ was defined for substrates 2,2-azino-bis-(3-ethylbenzthiazoline6-sulfonic acid) diammonium salt (ABTS), syringaldazine, guaiacol and 2,6-dimethoxyphenol (DMP).

The thermal stability was determined by incubating enzymes in distilled water at $25-90{ }^{\circ} \mathrm{C}$ for $30-60 \mathrm{~min}$; the $\mathrm{t}_{1 / 2}$ evaluation was performed at $50^{\circ} \mathrm{C}$. ABTS was used as model substrate.

\subsection{Dye decolorization}


Five dyes were used: the anthraquinonic Acid Blue 62 (AB62, $\lambda_{\max } 569-638 \mathrm{~nm}$ ) and Reactive Blue 19 (RB19, $\left.\lambda_{\max } 594-630 \mathrm{~nm}\right)$ and the azoic Acid Black 194 (AB194, $\left.\lambda_{\max } 570 \mathrm{~nm}\right)$, Acid Red 266 (AR266, $\left.\lambda_{\max } 570 \mathrm{~nm}\right)$ and Acid Yellow 49 (AY49, $\lambda_{\max } 398 \mathrm{~nm}$ ). Dye solutions (500 ppm) were prepared in distilled water. The enzymatic concentration ranged from 1 to $10 \mathrm{U} / \mathrm{ml}$.

The simulated textile wastewater (SW) was prepared to mimic an acid bath for wool dyeing, in accordance to (11) using three dyes (AB62, AR266, AY49) at $100 \mathrm{ppm}$ and $2 \mathrm{~g} / 1 \mathrm{Na}_{2} \mathrm{SO}_{4}$. The $\mathrm{pH}$ was adjusted at 5 with acetic acid and the solution was sterilized by tyndallization (three cycles of $60{ }^{\circ} \mathrm{C}$ for 60 min followed by $24 \mathrm{~h}$ cooling down).

The decolorization experiment was carried out in duplicate in 48-well flat-bottom microtiter plates and the final reaction volume was made up to $1 \mathrm{ml}$. Laccase activity was monitored during $24 \mathrm{~h}$ and decolorization (decolorization percentage, DP) was measured by monitoring the decrease of the absorbance under the maximum peak of each dye or under the whole wastewater spectrum area.

\subsection{Laccase pretreatment for cotton bleaching}

A combined approach of enzymatic and chemical bleaching was tested using cotton fabric specimens of $10 \mathrm{~cm}^{2}$ as substrate. The enzymatic treatment was performed with T. pubescens MUT 2400 culture filtrate $(1 \mathrm{U} / \mathrm{ml})$ or Denilite $^{\circledR}$ (Novozymes, Denmark) (1-8 U/ml) as reference, in sodium-acetate buffer $0.1 \mathrm{M}$ (pH 5) containing 1 $\mathrm{g} / \mathrm{l}$ surfactant. The treatment was carried out at $50{ }^{\circ} \mathrm{C}$ for $60 \mathrm{~min}$. Afterwards, the fabrics were bleached using $\mathrm{H}_{2} \mathrm{O}_{2} 40 \%(4 \mathrm{ml} / \mathrm{l})$ and $\mathrm{NaOH}(1.33 \mathrm{ml} / \mathrm{l})$ for $30 \mathrm{~min}$ at $98^{\circ} \mathrm{C}$. The White Index (WI\%) was spectrophotometrically measured in the $300-800 \mathrm{~nm}$ range following a standard protocol (UNI 7623).

\subsection{Analytical Methods}

During all the experiments, laccase activity was determined by following the oxidation of ABTS in sodiumcitrate buffer $\left(\mathrm{pH} 3\right.$ at $\left.25^{\circ} \mathrm{C}\right)$ at $420 \mathrm{~nm}\left(\varepsilon_{420}=36 \mathrm{mM}^{-1} \mathrm{~cm}^{-1}\right)$ in 96 -wells flat-bottom microtiter plates, using a microplate reader (SLT Spectra, Tecan, Crailsheim, Germany). Where indicated, the oxidation of syringaldazine at $525 \mathrm{~nm}\left(\varepsilon_{525}=65 \mathrm{mM}^{-1} \mathrm{~cm}^{-1}\right)$, guaiacol at $450 \mathrm{~nm}\left(\varepsilon_{450}=12.1 \mathrm{mM}^{-1} \mathrm{~cm}^{-1}\right)$ and DMP at $477 \mathrm{~nm}\left(\varepsilon_{477}=14.8\right.$ $\mathrm{mM}^{-1} \mathrm{~cm}^{-1}$ ) was followed (12). The activity was expressed in international units $(1 \mathrm{U}=1 \mu \mathrm{mol}$ of substrate oxidized per minute).

Glucose concentration was determined using the 2,4-dinitrosalicyclic acid assay for reducing sugars according to the method of (13) . 
Laccases were visualized by means of electrophoretic gels, loaded with $30 \mathrm{mU}$ per well. They were set in native conditions: $6 \%$ stacking gel and 12\% running gel were used and run at $80 \mathrm{~V}$ for $15 \mathrm{~min}$ and at $150 \mathrm{~V}$ for 105 min. At the end, the gel was stained with ABTS in sodium-citrate buffer at $\mathrm{pH} 3$ or using $\mathrm{AgNO}_{3}$ method (14).

\section{Results and Discussion}

\subsection{Effect of $\mathrm{Cu}$ and aromatic compounds}

As widely discussed in literature, media composition plays a central role in laccase production by fungi and $T$. pubescens metabolism is particularly sensitive to several external stimuli $(15,16)$. In this study, copper, veratryl alcohol and two dyes were used to stimulate the laccase production of T. pubescens MUT 2400, which was almost null (20 U/l) in the absence of any appropriate elicitors.

In accordance with other reports (15-18), $\mathrm{Cu}$ had a remarkable inducing effect on fungal enzyme synthesis, reaching up to $14 \pm 3 \mathrm{U} / \mathrm{ml}$ of laccases. In addition to metal ions, aromatic compounds may stimulate laccase production (1), probably due to the presence of recognized stress responsive elements on the gene promoter (6). In the present study, T. pubescens MUT 2400 only slightly responded to the single addition of VA, AB62 or $\mathrm{RB} 19(<0.19 \mathrm{U} / \mathrm{ml})$, but the combination of them with $\mathrm{Cu}$ triggered the fungal enzymatic machinery. This synergism led to laccase over-production, by far superior to the arithmetic sum of the single-inducer effect: $\mathrm{Cu}$ and VA together mildly stimulated enzymatic production $(37.5 \pm 6.6 \mathrm{U} / \mathrm{ml})$, but the highest laccase activity was measured in presence of $\mathrm{Cu}$ and dyes (AB62 53.3 $\pm 7.5 \mathrm{U} / \mathrm{ml}$; RB19 56.7 $\pm 11.3 \mathrm{U} / \mathrm{ml})$, equal up to 4-fold highest yields than in presence of $\mathrm{Cu}$ alone. When the two dyes stimulated laccase production (in combination with $\mathrm{Cu}$ ), they were in turn decolorized by the enzymes.

The inducers influenced not only the final amount of laccases secreted, but also the time course of laccase production. When the laccase production was low (i.e. RB19), the activity peak was observed at the very beginning of the experiment $\left(3^{\text {rd }}\right.$ day after the induction) and then gradually decreases. On the contrary, when the fungus was intensely stimulated ( $\mathrm{Cu}$ alone or coupled with one of the other aromatic compounds), laccase concentration constantly increased until the $14^{\text {th }}$ day of fermentation. This profile has been already observed by other authors in different Trametes species $(16,19)$.

\subsection{Effect of $\mathrm{Cu}, \mathrm{RB} 19$ and $\mathrm{N}$ combination}

Since T. pubescens MUT 2400 metabolism seemed to be influenced by several factors, the optimization of the laccase production was carried out using response surface methodology based on CCD, in order to explore at the same time the effect of many variables on laccase production. Copper and RB19 were taken into consideration, as well as nutrients. The composition of culture medium is indeed the first key factor able to influence laccases 
production. In particular, both carbon and nitrogen content represent critical factors $(1,5)$ and preliminary analysis using T. pubescens MUT 2400 confirmed it (data not shown). Proper nutritional conditions had to be precisely defined and balanced with the presence of other elicitors: specifically, different $\mathrm{C} / \mathrm{N}$ ratios (1-3) were here investigated by varying bactopeptone concentration.

The experimental design enabled to almost double the previously achieved yield (56 U/ml), with a maximal predicted laccase activity of $120 \mathrm{U} / \mathrm{ml}$ and an average space-time yield of $6 \mathrm{U} / \mathrm{ml}$ produced each day. The effect on space-time yields of $\mathrm{Cu}$ and $\mathrm{C} / \mathrm{N}$ ratio at a fixed RB19 concentration is shown in Figure 1a. The plot reveals that laccase productivity is maximized by high values of both the varying parameters: $1.2 \mathrm{mM}$ of $\mathrm{Cu}$ and $\mathrm{C} / \mathrm{N}$ ratio of 2.65 (18.7 mg/l of bactopeptone) turned out to be the optimal conditions for laccase production. The optimal $\mathrm{Cu}$ concentration predicted by the model fits perfectly within the average range $(1-2 \mathrm{mM})$ associated to T. pubescens strains (15). However in some studies, the presence of metal ions (close to $1.5 \mathrm{mM}$ ) caused a significant growth inhibition $(7,15)$, representing a strong limitation in the optimization of laccase production. Contrary to this evidence, the present study showed no growth inhibition related to $\mathrm{Cu}$ addition (data not shown), highlighting the resilience of the strain to this kind of stress.

The effect of $\mathrm{RB} 19$ and $\mathrm{C} / \mathrm{N}$ ratio at a fixed $\mathrm{Cu}$ concentration on space-time yields is shown in Figure $1 \mathrm{~b}$. The same behavior was observed plotting $\mathrm{RB} 19$ and $\mathrm{Cu}$ at a fixed $\mathrm{C} / \mathrm{N}$ ratio (data not shown). The optimal condition was still not reached because the best results were found at the highest tested RB19 concentration $(0.4 \mathrm{mM})$. On the whole, the three factors similarly influenced the two response variables monitored. The capability of the fungus to respond to several stimuli probably found its reason in the fungal physiological habitat, where heterogeneous nourishment sources, minerals and lignin derivates (i.e. as dyes) are present and affect the secondary metabolism. Even though the amplitude of the potential synergism among factors is difficult to define in advance, this phenomenon has been observed in several studies $(6,18,20)$.

Since the model used experimental data to make assumptions of a real behavior, it is important to investigate if the results predicted by the model approximately fit with experimental ones. The calculated coefficients of variation $\left(\mathrm{R}^{2}\right)$ for the two responses were $0.9587\left(Y_{1}\right)$ and $0.9504\left(Y_{2}\right)$, showing that the quadratic equation (Eq. 1) was able to well correlate model predicted data with actual values. The analysis of variance (ANOVA) was carried out and as hypothesized, the significance of the model was acquired at p-value lower than 0.05. Linear, squared and coupled effects were significant on laccase production: $\mathrm{Cu}, \mathrm{RB} 19$ and $\mathrm{C} / \mathrm{N}$ ratio were all relevant on the two dependent responses considered in the present study and a clear synergism among them was also demonstrated ( $\mathrm{p}<0.05$ for $X_{1} * X_{2}, X_{2} * X_{3}$ and $\left.X_{1} * X_{3}\right)$. Furthermore, lack of fit evaluation $(\mathrm{P}=0.1545$ and 
0.4074 for $Y_{1}$ and $Y_{2}$, respectively) confirmed that the chosen model was correct and it was appropriate to describe data variation.

Even though the model fixed optimal conditions of $\mathrm{Cu}$ and $\mathrm{C} / \mathrm{N}$ ratio, these results indicated that laccase production could be further enhanced by increasing RB19 concentration. The effect of this single parameter was thus assessed in a broad concentration range $(0.4-2.0 \mathrm{mM})$, setting the highest tested concentration in order to avoid any toxic effects on the fungal biomass growth and solubility troubles in dye stock solutions preparation. The fungus did not linearly respond to the dye concentration increase: no significant difference was detected between 0.5 and $1.0 \mathrm{mM}(68-78 \mathrm{U} / \mathrm{ml})$, whereas the highest tested RB19 concentration was also the optimal one (at $2.0 \mathrm{mM}, 160.2 \pm 14.9 \mathrm{U} / \mathrm{ml}$ ).

Under these conditions, a characteristic culture profile could be drawn on the basis of laccase activity, $\mathrm{pH}$ and glucose concentration data (Figure 2). The maximal enzymatic production occurred during the second week of culturing, and corresponded to the rising of $\mathrm{pH}$ to neutral values (from 3.8 to 7.6 ) and to complete depletion of glucose from the culture medium (only $1 \%$ left of the initial concentration at $13^{\text {th }}$ day). This culture evolution has been already observed by other authors $(3,16-17)$, introducing the energy-saving response as one of the possible explanation to this phenomenon. It has been suggested (21) that only in starvation condition, the sustenance of the culture passes by alternative carbon sources and the expression of some proteins (i.e. laccases) is stimulated. This assumption found new confirmations by the recent discovery of CreA-like binding sites on several laccase promoters (6).

\subsection{Scale-up of the laccase production}

On the basis of the previously optimized culture conditions ( $\mathrm{C} / \mathrm{N}$ ratio $2.65, \mathrm{Cu} 1.2 \mathrm{mM}, \mathrm{RB} 192.0 \mathrm{mM})$, the laccase production was scaled up to 101 reactor along with parallel $500 \mathrm{ml}$ shaken flask runs. In the fermenter, the laccase production was delayed $\left(9^{\text {th }}\right.$ day) in comparison to the shaken flasks $\left(3^{\text {rd }}-6^{\text {th }}\right.$ days $)$. Moreover, the maximal laccase activity $(290 \mathrm{U} / \mathrm{ml})$ was obtained in $500 \mathrm{ml}$ flasks, which resulted 3-fold higher than in the 101 reactor $(95 \mathrm{U} / \mathrm{ml})$. Up to date, the maximal obtained productivity $(300 \mathrm{U} / \mathrm{ml})$ fits among the best results available in literature $(18,22)$; a $T$. pubescens strain expressed higher enzymatic activity $(740 \mathrm{U} / \mathrm{ml})$ only by fed-batch fermentation (16).

Besides, the enzymatic production did not only differ in terms of final productivity but also from a qualitative point of view: two and three bands with laccase activity were produced by T. pubescens MUT 2400 in the reactor and in flask, respectively. 
In general, these results pointed out the possibility to increase the laccase production by upscaling the fungal growth: when grown in $500 \mathrm{ml}$ flasks, the fungus produced 1.7 -fold more laccases than in $100 \mathrm{ml}$ flask. The established culture conditions (i.e. amount of the broth in flask, air exchange, etc.) had a positive effect on laccase production. Unfortunately, this trend was not maintained in the reactor, where the productivity significantly dropped down. Interestingly, these lower yields were associated to the modification of the fungal morphology: in contrast to the flask cultures where the growth form has been always as small and compact pellets, in the reactor the fungus grew as mycelial aggregates and loose broken hyphae. Although a precise correlation between fungal morphology and enzymes production has not been demonstrated yet, many evidences observed an empirical relationship among them (23-24).

Taken all together, the data shown in this study indicate that cultivation medium and the elicitors were adequate, whereas the operational conditions set in the reactor were not. The same problems occurred during Trametes multicolor growth: the mechanical stresses caused by the impellers significantly limited the capability of the fungus to produce large amount of enzymes and changed the pellet morphology (17). Hence, the process yields may be further increased by optimizing the reactor configuration (aeration and agitation rate, typology of stirrers, etc.).

\subsection{Enzymatic characterization}

The culture supernatant produced in the 101 fermenter was analyzed for the optimum and the stability in a wide range of $\mathrm{pH}$ and temperatures. In fact, for practical applications of laccases as biocatalysts, it is important to know the stability of its activity under specific operative conditions: i.e. the $\mathrm{pH}$ of textile industrial wastewaters can vary substantially (25). Laccases were stable over 6 months storage at $4{ }^{\circ} \mathrm{C}$ with a recovery of more than $60 \%$ of the initial activity.

To estimate the optimum $\mathrm{pH}$ of laccase crude extract, four compounds were used, including phenols as syringaldazine, guaiacol and DMP in addition to ABTS (Figure 3). As expected, ABTS oxidation was maximal at acidic $\mathrm{pH}$ (2.5). In contrast, the $\mathrm{pH}$ optimum for the other substrates was higher: a bell-shape $\mathrm{pH}$ profile with the maximum peak at 4.0-5.0-5.5 was observed for DMP, guaiacol and syringaldazine, respectively. These data are in accordance to most of the known laccases whose $\mathrm{pH}$ optimum is in an acidic range for ABTS and in a more alkaline interval (from $\mathrm{pH} 4$ to 7 ) for phenol compounds (12).

The effect of $\mathrm{pH}$ on the enzymatic stability $\left(\mathrm{t}_{1 / 2}\right)$ is reported in Table 2 . At acidic $\mathrm{pH}(<5)$, enzymes inactivated very fast, i.e. $\mathrm{t}_{1 / 2}$ was closed to $7 \mathrm{~min}$ at $\mathrm{pH} 2$. It is interesting to notice that at $\mathrm{pH} 3, \mathrm{ABTS}$ oxidation was very high $(82 \%$ in comparison to $\mathrm{pH} 2.5)$ (Figure 3), even though laccases lost more than $40 \%$ of their activity within 
the first $6 \mathrm{~h}$ (Table 2). As demonstrated by other authors, enzymatic activity was more stable in a neutralslightly basic environment: between pH 6 and 8, laccases were stable for long incubation periods, even up to 2 months at $\mathrm{pH}$ 6. Similarly, in a $\mathrm{pH}$ range from 6 to $10,70 \%$ of final activity recovery of Lentinus laccases was obtained (26). Laccase of Pycnoporus sanguineus and Pycnoporus coccineus were slightly influenced by $\mathrm{pH}$, showing at least $80 \%$ of residual activity in a $\mathrm{pH}$ range of 5-7 (27). However, in both cases case, $\mathrm{t}_{1 / 2}$ was not determined, since the experiment was followed for few days only. To the authors' knowledge, this is the first comprehensive study on laccase stability at different $\mathrm{pH}$.

Thermal optimum was investigated by incubating enzymes at $25-90^{\circ} \mathrm{C}$ for different time: the maximal activity was reached at $50{ }^{\circ} \mathrm{C}$ (Table 2). The enzyme activity sharply decreased when temperature rose above $70{ }^{\circ} \mathrm{C}$. In comparison with other fungal strains, T. pubescens MUT 2400 enzymes showed interesting potential, being active at limiting conditions for other enzymes. For example, laccases of Pleurotus sajor-caju lost more than $80 \%$ of their activity already after $30 \mathrm{~min}$ incubation at $60{ }^{\circ} \mathrm{C}(28)$. Ten minutes at $60{ }^{\circ} \mathrm{C}$ was enough to loose most of the activity (90\%) of laccases of Pleurotus ostreatus (29). However, more thermostable laccases have been described, as for example, Trametes versicolor where $\mathrm{t}_{1 / 2}$ was $2.2 \mathrm{~h}$ at $70{ }^{\circ} \mathrm{C}(30)$.

The activity half-life $\left(\mathrm{t}_{1 / 2}\right)$ at $50{ }^{\circ} \mathrm{C}$ was $14 \mathrm{~h}$, being much better than most of the data in literature, which range from few minutes to several hours: $40 \mathrm{~min}$ in P. sajor-caju (28), $4.5 \mathrm{~h}$ in Panus tigrinus (31) and more than $8 \mathrm{~h}$ in $T$. versicolor and $T$. pubescens $(3,30)$. Only few studies reported more stable enzymes at $50^{\circ} \mathrm{C}$ : for example, the $\mathrm{t}_{1 / 2}$ of purified laccases of Trametes ochracea, Trametes hirsuta, Cerrena maxima and Coriolopsis fulvocinerea was closed to $50 \mathrm{~h}$ (32). In general, the slow inactivation at high temperature makes these enzymes a valuable tool for the application in processes requiring high (at least $50{ }^{\circ} \mathrm{C}$ ) operative temperatures.

\subsection{Dye decolorization}

Dyes release in the environment is a serious current issue and an enzymatic treatment represents a promising eco-friendly approach, displaying low energy requirements and easy process control. In the present study, both anthraquinonic and azoic dyes were taken into account in order to examine the most commonly employed compounds in textile industry.

Anthraquinonic dyes AB62 and RB19 were optimal substrates for laccase-mediated oxidation: the final decolorization yields were higher than $80 \%$, irrespective of the enzyme concentration used (Figure 4). As previously reported (33), the AB62 breakdown by T. pubescens MUT 2400 laccases proceeded with the formation of a red metabolite, obtained probably by the dimerization of two dye molecules, which was eventually converted into colorless metabolite. Interestingly, laccases mediated a similar degradation profile 
also for RB19, producing a red-colored intermediate. A recent report explained and investigated the RB19 transformation pathway, but this red metabolite was not described (34).

The time course of the reactions was followed showing a different reactivity of the enzymes towards the dyes. The fastest reaction was achieved for AB62, showing $80 \%$ of color removal already within the first 5 min by 10 $\mathrm{U} / \mathrm{ml}$ of laccases. Decreasing the enzymatic concentration, the process resulted slightly slowed, achieving the same results within 4 h. Regarding RB19, the color gradually decreased but despite the used enzymatic concentrations, the maximal yield (DP 95\%) was always reached within the first 4 h. Dye decolorization effectiveness of T. pubescens MUT 2400 crude extract is highlighted by comparing with the data available in literature: during the same incubation time, $10 \mathrm{U} / \mathrm{ml}$ of laccase from Polyporus brumalis removed 35\% of RB19 (35) whereas $88 \%$ of decolorization was observed in presence of $20 \mathrm{U} / \mathrm{ml}$ of Lentinus sp. (26). With azoic dyes, similar results (DP > 80\%) were obtained only for AB194, even though high enzyme concentrations $(5-10 \mathrm{U} / \mathrm{ml})$ and longer treatment time $(24 \mathrm{~h})$ were needed (Figure 4$)$. The enzymatic treatment was ineffective towards $500 \mathrm{ppm}$ of AR266, whereas at $100 \mathrm{ppm}, 5$ and $10 \mathrm{U} / \mathrm{ml}$ of laccases removed 15 and $22 \%$ of the color, respectively. No effect was observed towards AY49, confirming its high resistance to oxidation reactions mediated by fungi and their enzymes already reported in other studies (11). Actually, difficulties to treat azo dyes by laccases have been already widely reported (36), and may find an explanation by looking at the chemical structures of the dyes themselves. In accordance to the exhaustive discussion about the role of the electron-donating groups present in the rings by (36), some assumptions could be done. Hence, the two hydroxyl groups of AB194 are strong electron-donating groups and favored the enzymatic oxidation, whereas the halogen groups and the pyrazole ring (AR266 and AY49) inhibited dyes degradation. Moreover, laccase treatment confirmed to be a stable system, displaying only a minimal activity loss $(<10 \%)$ over the experiment, and no destabilizing effect may be associated to the initial dye concentration or the chemical nature of the treated dye.

As further validation of the laccase decolorization capability, a simulated wastewater (SW) was also used. The final decolorization yields (DP closed to 30\%) were similar irrespective of the used laccase concentration. It is interesting to highlight that the enzymatic treatment was never efficient as a whole cell approach: SW treatment by means of $T$. pubescens MUT 2400 (maximum enzymatic activity $0.25 \mathrm{U} / \mathrm{ml}$ ) removed $44 \%$ of the color. In detail, AB62 was completely degraded, AY49 was not modified at all, whereas only the fungus led to an extensive reaction towards AR266. It could be hypothesized that the complex fungal machinery worked better 
than the crude extract because of the specific activation of certain pathways in respond to the treated dyes, i.e. secreting specific mediators with a high redox potential.

\subsection{Bleaching of cotton}

Along the textile manufacturing process, laccases may have fruitful applications also in the preparation of cotton fabrics, removing non-cellulosic impurities and enhancing the whiteness and the wettability of the fibers. Nowadays, traditional bleaching methodologies are based on $\mathrm{H}_{2} \mathrm{O}_{2}$ but running at alkaline $\mathrm{pH}$ and high temperature, $\mathrm{NaOH}$ and stabilizers are also needed. The basic $\mathrm{pH}$ can damage the fibers and high water volumes are consumed during several washing steps (37). Thus, traditional treatments alone need large amounts of chemicals, energy and water, increasing, of course, the final process costs. However, coupling chemical and enzymatic treatments, the actual consumption of $\mathrm{H}_{2} \mathrm{O}_{2}$ and water is reduced, increasing the environmental sustainability of the process (37).

In the present study, enzymatic treatment enhanced the whiteness yield obtained by conventionally bleached fibers (no enzymatic pretreatment): the White Index percentage (WI\%) rose from 6.2 to 26.9 when the enzymes were applied (Figure 5). These results are in agreement with previous investigations, where laccases of Trametes villosa were successfully applied to pretreat cotton fabrics: the use of this additional treatment worth because even reducing the $\mathrm{H}_{2} \mathrm{O}_{2}$ amount of more than half, the whitening yields were comparable to the conventional methodology ones (38).

Thereby, the effectiveness of T. pubescens MUT 2400 laccases was compared with a commercial enzymatic formulate, i.e. Denilite ${ }^{\circledR}$ (Novozymes, Denmark). At the same concentration $(1 \mathrm{U} / \mathrm{ml})$, here studied laccases were more efficient than Novozyme's ones, causing almost a 2-fold higher WI\%. Only overloading the Denilite ${ }^{\circledR}$ treatment $(8 \mathrm{U} / \mathrm{ml})$, the achieved degree of white was comparable (WI\% $25 \%$ ) with the results obtained by T. pubescens MUT 2400 laccases $(1 \mathrm{U} / \mathrm{ml})$. As already discussed (38), a possible explanation of the role of laccase in cotton bleaching may be the transformation of lignin residues and flavonoids into colored intermediates, whose further conversion in colorless compounds becomes much easier by means of the further chemical bleaching. This represents just a preliminary study, but further optimization steps may allow consistently decreasing the required $\mathrm{H}_{2} \mathrm{O}_{2}$, with positive repercussions on the costs and the environmental sustainability of the entire process.

\section{Conclusions}


When opportunely stimulated, $T$. pubescens produced elevate laccases amount (up to $300 \mathrm{U} / \mathrm{ml}$ ). A CCD helped to define the optimal culture conditions but alternative configurations to stirrer tank reactor deserve further investigations.

The broad substrate specificity and the $\mathrm{pH}$ and temperature stability of laccases justified their use in the textile manufacturing system. They rapidly decolorized both anthraquinonic and azoic dyes: for at least three of them, $80 \%$ of the color was removed within the first $4 \mathrm{~h}$.

Besides the whiteness of fibers improved when the enzymatic pretreatment was applied: these laccases worked better than commercial ones. 


\section{References}

(1) Strong, P.J.; Claus, H. Laccase: a review of its past and its future in bioremediation. Crit. Rev. Env. Sci. Technol. 2010, 41, 373-434.

(2) Mikolasch, A.; Niedermeyer, T.H.J.; Lalk, M.; Witt, S.; Seefeldt, S; Hammer, E.; Schauer, F.; Gesell, M.; Hessel, S.; Julich, W-D.; Lindequist, U. Novel penicillins synthetized by biotransformation using laccase from Trametes spec. Chem. Pharm. Bull. 2006, 54, 632-638.

(3) Gaitan, I.A.; Medina, S.C.; González, J.C.; Rodríguez, A.; Espejo, A.J.; Osma, J.F.; Sarria, V.; AlmécigaDíaz, C.J.; Sánchez, O.F. Evaluation of toxicity and degradation of a chlorophenol mixture by the laccase produced by Tra;metes pubescens. Bioresour. Technol. 2011, 102, 3632-3635.

(4) Mir-Tutusaus, J.A.; Masís-Mora, M.; Corcellas, C.; Eljarrat, E.; Barceló, D.; Sarrà, M.; Caminal, G.; Vicent, T.; Rodríguez-Rodríguez, C.E. Degradation of selected agrochemicals by the white rot fungus Trametes versicolor. Sci. Total Environ. 2014, 500-501, 235-242.

(5) Majeau, J.; Brar, S.K.; Tyagi, R.D. Laccases for removal of recalcitrant and emerging pollutants. Bioresour. Technol. 2010, 101, 2331-2350.

(6) Piscitelli, A.; Giardina, P.; Lettera, V.; Pezzella, C.; Sannia, G.; Faraco, V. Induction and transcriptional regulation of laccases in fungi. Curr. Genomics 2011, 12, 104-112.

(7) Baldrian, P.; Gabriel, J. Copper and cadmium increase laccase activity in Pleurotus ostreatus. FEMS Microbiol. Lett. 2002, 206, 69-74.

(8) Bertrand, B.; Martìnez-Morales, F.; Trejo-Hernàndez, M.R. Fungal laccases: induction and production. Rev. Mex. Ing. Quím. 2014, 12 (3), 473-488.

(9) Anastasi, A.; Spina, F.; Romagnolo, A.; Tigini, V.; Prigione, V.; Varese, G.C. Integrated fungal biomass and activated sludge treatment for textile wastewaters bioremediation. Bioresour. Technol. 2012, 123, 106-111.

(10) Nair, R.; Demarche, P.; Agathos, S.N. Formulation and characterization of an immobilized laccase biocatalyst and its application to eliminate organic micropollutants in wastewater. New Biotechnol. 2013, 30 (6), $814-823$

(11) Anastasi, A.; Prigione, V.; Varese, G.C. Industrial dye degradation and detoxification by basidiomycetes belonging to different eco-physiological groups. J. Hazard. Mater. 2010, 177 (1-3), 260-267.

(12) Ullrich, R.; Huong, L.M.; Dung, N.L.; Hofrichter, M. Laccase from the medicinal mushroom Agaricus blazei: production, purification and characterization. Appl. Microbiol. Biotechnol. 2005, 67, 357-363. 
(13) Miller, G.L. Use of dinitrosalicylic acid reagent for determination of reducing sugar. Anal. Chem. 1959, 31, $426-428$.

(14) Yaver, D.S.; Xu, F.; Golightly, E.J.; Brown, K.M.; Brown, S.H.; Rey, M.W.; Cheider, P.; Halkier, T.; Mondorf, K.; Dalboge, H. Purification, characterization, molecular cloning and expression of two laccase genes from the white-rot basidiomycete Trametes villosa. Appl. Environ. Microbiol. 1996, 62, 834-841.

(15) Galhaup, C.; Haltrich, D. Enhanced formation of laccase activity by the white-rot fungus Trametes pubescens in the presence of copper. Appl. Microbiol. Biotechnol. 2001, 56, 225-232.

(16) Galhaup, C.; Wagner, H.; Hinterstoisser, B.; Haltrich, D. Increased production of laccase by the wooddegrading basidiomycete Trametes pubescens. Enzyme Microb. Technol. 2002, 30, 529-536.

(17) Hess, J.; Leitner, C.; Galahup, C.; Kulbe, K.D.; Hinterstoisser, B.; Steinwender, M.; Haltrich, D. Enhanced formation of extracellular laccase activity by the white rot fungus Trametes versicolor. Appl. Biochem.

Biotechnol. 2002, 98-10, 229-241.

(18) Junghanns, C.; Parra, R.; Keshavarz, T.; Schlosser, D. Towards higher laccase activities produced by aquatic ascomycetous fungi through combination of elicitors and an alternative substrate. Eng. Life Sci. 2008, 3, 277-285.

(19) Enayatzamir, K.; Alikhani, H.A.; Rodriguez-Couto, S. Simultaneous production of laccase and decolouration of the diazo dye Reactive Black 5 in a fixed bed reactor. J. Hazard. Mater. 2009, 164, 296-300. (20) Ramìrez-Cavazos, L.I.; Junghanns, C.; Nair, R.; Càrdenas-Chàvez, D.L.; Hernàndez, L.; Agathos, S.N.; Parra, R. Enhanced production of thermostable laccases from a native strain of Pycnoporus sanguineus using central composite design. J. Zhejiang Univ. Sci. B 2014, 15 (4), 343-352.

(21) Ronne, H. Glucose repression in fungi. Trends Genet. 1995, 11, 12-17.

(22) Zucca, P.; Rescigno, A.; Olianas, A.; Maccioni, S.; Sollai, F.A.; Sanjust, E. Induction, purification, and characterization of a laccase isozyme from Pleurotus sajor-caju and the potential in decolorization of textile dyes. J. Mol. Catal. B: Enzym. 2011, 68, 216-222.

(23) Thiruchelvam, A.T.; Ramsay, J.A. Growth and laccase production kinetics of Trametes versicolor in a stirred tank reactor. Appl. Microbiol. Biotechnol. 2007, 74, 547-554.

(24) Kim, J.; Song, H. Effect of fungal pellet morphology on enzyme activities involved in phthalate degradation. J. Microbiol. 2009, 47, 420-424.

(25) Vanhulle, S.; Trovaslet, M.; Enaud, E.; Lucas, M.; Taghavi, S.; van der Lelie, D.; van Aken, B.; Foret, M.; Onderwater, R.C.A.; Wesenberg, D.; Agathos, S.N.; Schneider, Y.; Corbisier, A. Decolorization, cytotoxicity, 
and genotoxicity reduction during a combined ozonation/fungal treatment of dye-contaminated wastewater. Environ. Sci. Technol. 2008, 42, 584-589.

(26) Hsu, C.; Wen, T.; Su, Y.; Jiang, Z.; Chen, C.; Shyur, L. Biological degradation of anthraquinone and azo dyes by a novel laccase from Lentinus sp. Environ. Sci. Technol. 2012, 25, 761-769.

(27) Uzan, E.; Nousiainen, P.; Balland, V.; Sipila, J.; Piumi, F.; Navarro, D.; Asther, M.; Record, E.; Lomascolo, A. High redox potential laccases from the ligninolytic fungi Pycnoporus coccineus and Pycnoporus sanguineus suitable for white biotechnology: from gene cloning to enzyme characterization and applications. J. Appl. Microbiol. 2009, 108, 2199-2213.

(28) Murugesan, K.; Arulmani, M.; Nam, I.; Kim, Y.; Chang, Y.; Kalaichelvan P. Purification and characterization of laccase produced by a white rot fungus Pleurotus sajor-caju under submerged culture condition and its potential in decolorization of azo dyes. Appl. Microbiol. Biotechnol. 2006, 72, 939-946. (29) Liu, L.; Lin, Z.; Zheng, T.; Lin, L.; Zheng, C.; Lin, C.; Wang, S.; Wang, Z. Fermentation optimization and characterization of the laccase from Pleurotus ostreatus strain 10969. Enzyme Microb. Technol. 2009, 44, 426433.

(30) Youshuang, Z.; Haibo, Z.; Mingle, C.; Zhenzhen, W.; Feng, H.; Peiji, G. Production of a thermostable metal-tolerant laccase from Trametes versicolor and its application in dye decolorization. Biotechnol. Bioprocess Eng. 2011, 16, 1027-1035.

(31) D'Annibale, A.; Quaratino, D.; Federici, F.; Fenice, M. Effect of agitation and aeration on the reduction of pollutant load from olive-mill wastewater by the white-rot fungus Panus tigrinus. Biochem. Eng. J. 2006, 29, $243-249$

(32) Shleev, S.V.; Morozova, O.V.; Nikitina, O.V.; Gordhina, E.S.; Rusinova, T.V.; Serezhenov, V.A.; Burbaev, D.S.; Gazaryan, I.G.; Yaropolov, A.I. Comparison of physico-chemical characteristics of four laccases from different basidiomycetes. Biochimie 2004, 86, 693-703.

(33) Vanhulle, S.; Trovaslet, M.; Enaud, E.; Lucas, M.; Sonveaux, M.; Decock, C.; Onderwater, R.; Schneider, Y.; Corbisier, A. Cytotoxicity and genotoxicity evolution during decolorization of dyes by white rot fungi. World J. Microbiol. Biotechnol. 2008, 24, 337-344.

(34) Osma, J.F.; Moilanen, U.; Toca-Herrera, J.; Rodrıguez-Couto, S. Morphology and laccase production of white-rot fungi grown on wheat bran flakes under semi-solid-state fermentation conditions. FEMS Microbiol. Lett. $2011,318,27-34$. 
(35) Kim, H.; Lee, S.; Ryu, S.; Choi, H.T. Decolorization of remazol brilliant blue R by a purified laccase of Polyporus brumalis. Appl. Biochem. Biotechnol. 2012, 166, 159-164.

(36) Ciullini, I.; Tilli, S.; Scozzafava, A. Fungal laccase, cellobiose dehydrogenase, and chemical mediators: combined actions for the decolorization of different classes of textile dyes. Bioresour. Technol. 2008, 99, 70037010.

(37) Araujo, R.; Casal, M.; Cavaco-Paulo, A. Application of enzymes for textile fibres processing. Biocatal. Biotransform. 2008, 26, 332-349.

(38) Tzanov, T.; Basto, C.; Gubitz, G.M.; Cavaco-Paulo, A. Laccases to improve the whiteness in a conventional bleaching of cotton. Macromol. Mat. Eng. 2003, 288, 807-810. 
Table 1.

\begin{tabular}{cccccc}
$\mathbf{R u n}$ & $\begin{array}{c}\boldsymbol{X}_{\mathbf{1}} \\
\mathbf{C u}(\mathbf{m M})\end{array}$ & $\begin{array}{c}\boldsymbol{X}_{\mathbf{2}} \\
\mathbf{R B 1 9}(\mathbf{m M})\end{array}$ & $\begin{array}{c}\boldsymbol{X}_{\mathbf{3}} \\
\mathbf{C} / \mathbf{N}\end{array}$ & $\begin{array}{c}\boldsymbol{Y}_{\mathbf{1}} \\
\text { max activity }\end{array}$ & $\begin{array}{c}\boldsymbol{Y}_{\mathbf{2}} \\
\text { space-time yield }\end{array}$ \\
\hline $\mathbf{1}$ & 1.2 & 0.4 & 1 & 46867 & 2464 \\
$\mathbf{2}$ & 0.65 & 0.25 & 3 & 65684 & 3159 \\
$\mathbf{3}$ & 1.2 & 0.1 & 3 & 65047 & 3129 \\
$\mathbf{4}$ & 0.1 & 0.1 & 3 & 26559 & 1785 \\
$\mathbf{5}$ & 0.65 & 0.25 & 2 & 77097 & 4500 \\
$\mathbf{6}$ & 0.65 & 0.1 & 2 & 62663 & 3396 \\
$\mathbf{7}$ & 0.65 & 0.25 & 1 & 38510 & 2306 \\
$\mathbf{8}$ & 1.2 & 0.1 & 1 & 31339 & 1809 \\
$\mathbf{9}$ & 0.1 & 0.4 & 3 & 47589 & 3059 \\
$\mathbf{1 0}$ & 1.2 & 0.4 & 3 & 108774 & 5314 \\
$\mathbf{1 1}$ & 0.1 & 0.4 & 1 & 30736 & 1921 \\
$\mathbf{1 2}$ & 0.1 & 0.25 & 2 & 47328 & 2816 \\
$\mathbf{1 3}$ & 0.65 & 0.4 & 2 & 97297 & 5359 \\
$\mathbf{1 4}$ & 0.1 & 0.1 & 1 & 22581 & 1411 \\
$\mathbf{1 5}$ & 1.2 & 0.25 & 2 & 74397 & 3912 \\
\hline
\end{tabular}


Table 2.

\begin{tabular}{ccccc} 
& & & \multicolumn{2}{c}{ residual activity \% } \\
$\mathbf{p H}$ & $\mathbf{t}_{\mathbf{1} / \mathbf{2}}$ & $\mathbf{T}$ & $\mathbf{3 0}$ min & $\mathbf{6 0}$ min \\
\hline 2 & 7 min & $25^{\circ} \mathrm{C}$ & 102 & 100 \\
3 & $6 \mathrm{~h}$ & $40^{\circ} \mathrm{C}$ & 112 & 110 \\
4 & $24 \mathrm{~h}$ & $50^{\circ} \mathrm{C}$ & 116 & 119 \\
5 & $98 \mathrm{~h}$ & $60^{\circ} \mathrm{C}$ & 111 & 110 \\
6 & 64 days & $70^{\circ} \mathrm{C}$ & 58 & 46 \\
7 & 46 days & $80^{\circ} \mathrm{C}$ & 2 & 0 \\
8 & 25 days & $90^{\circ} \mathrm{C}$ & 0 & 0 \\
\hline
\end{tabular}


Table 1. Experimental conditions of the central composition experimental design.

Table 2. Stability of T. pubescens MUT 2400 laccases: determination of $\mathrm{pH}\left(\mathrm{t}_{1 / 2}\right)$ and temperature (residual activity $\%$ after the incubation at different temperatures $25-90{ }^{\circ} \mathrm{C}$ for $30-60 \mathrm{~min}$ ). 

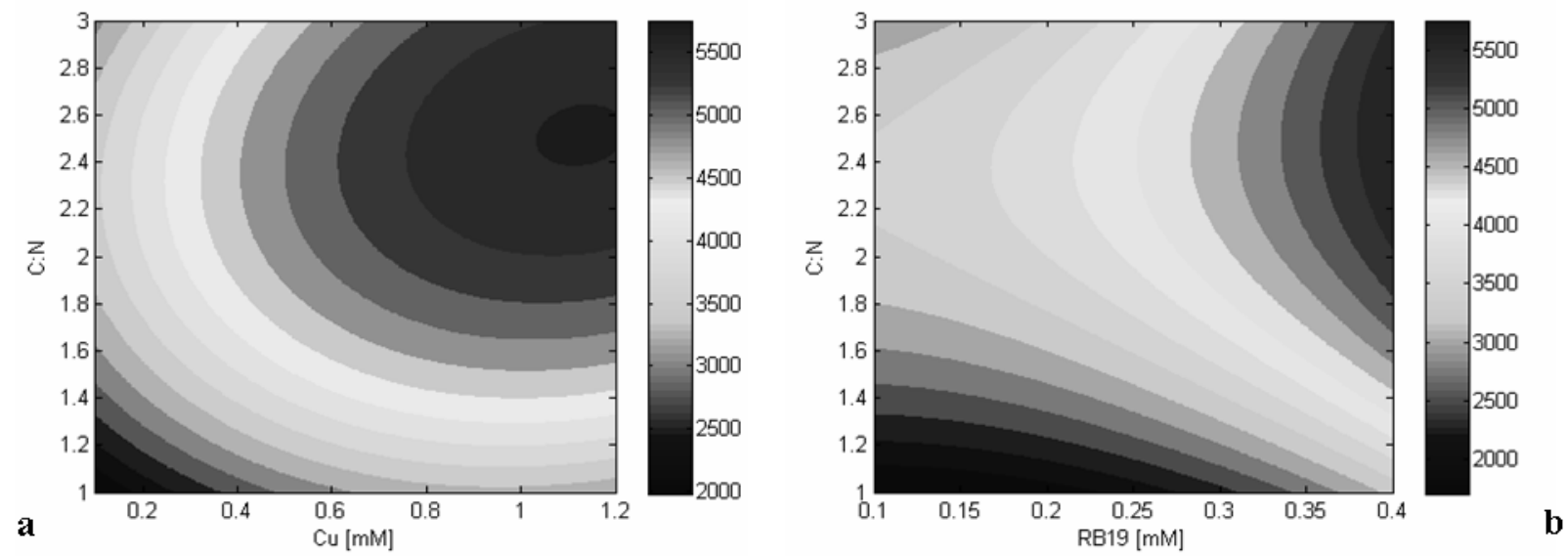

Figure 1. 


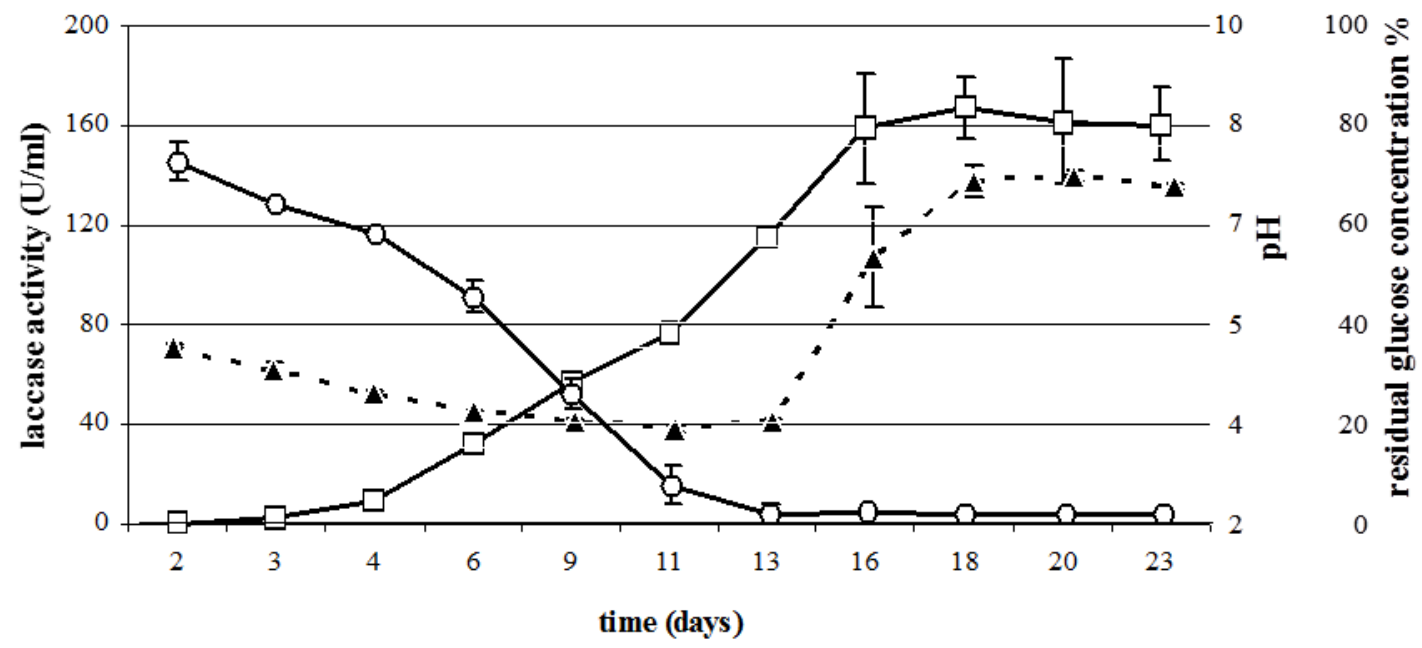

Figure 2. 

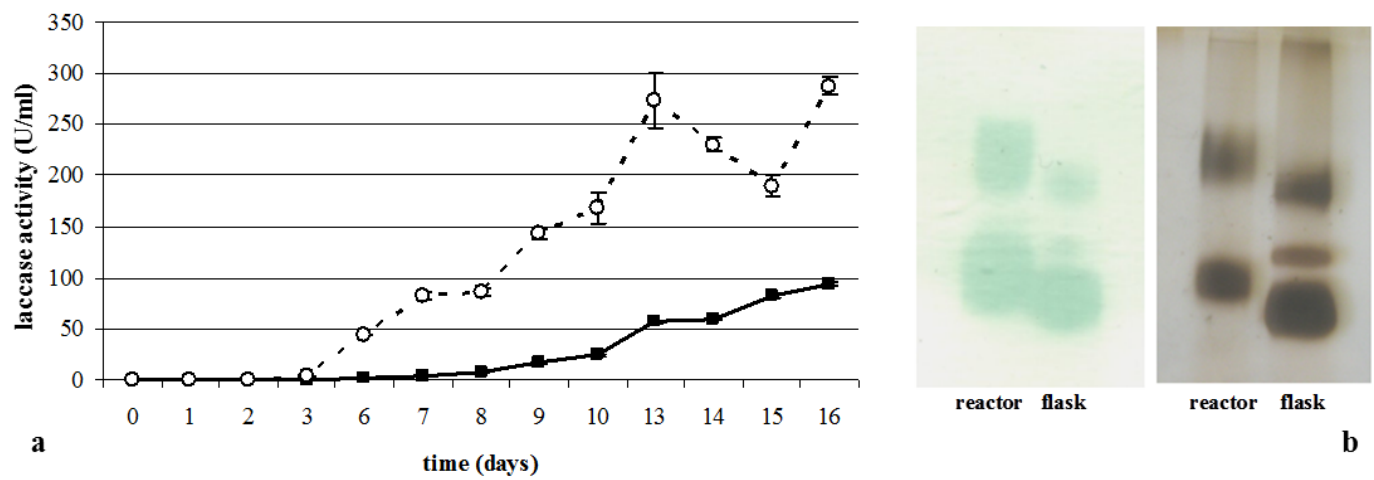

Figure 3. 


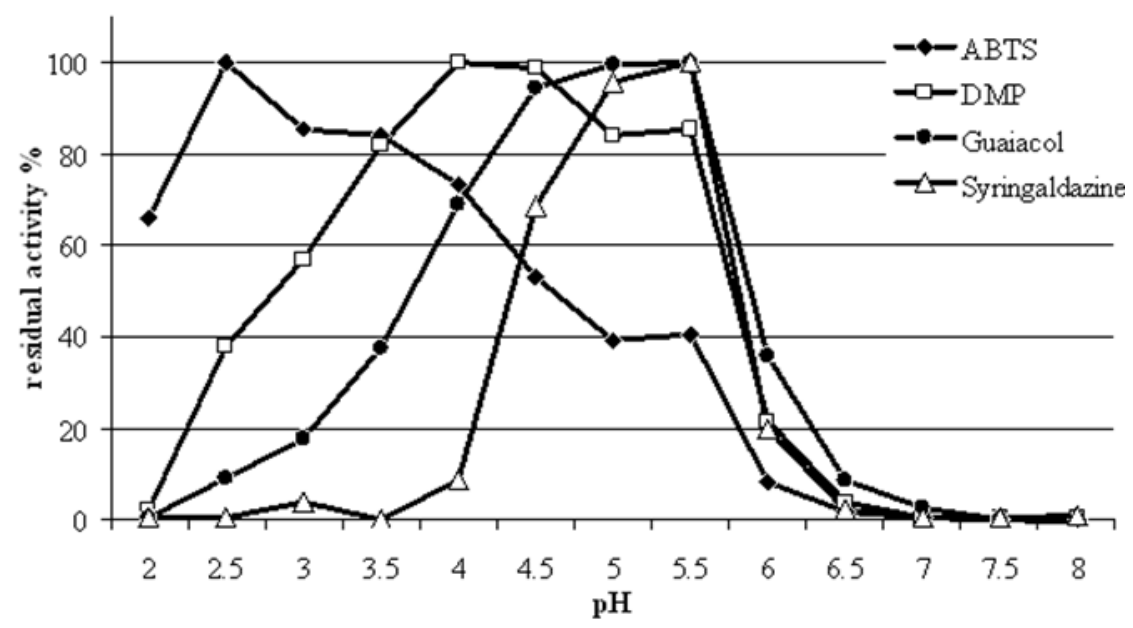

Figure 4. 

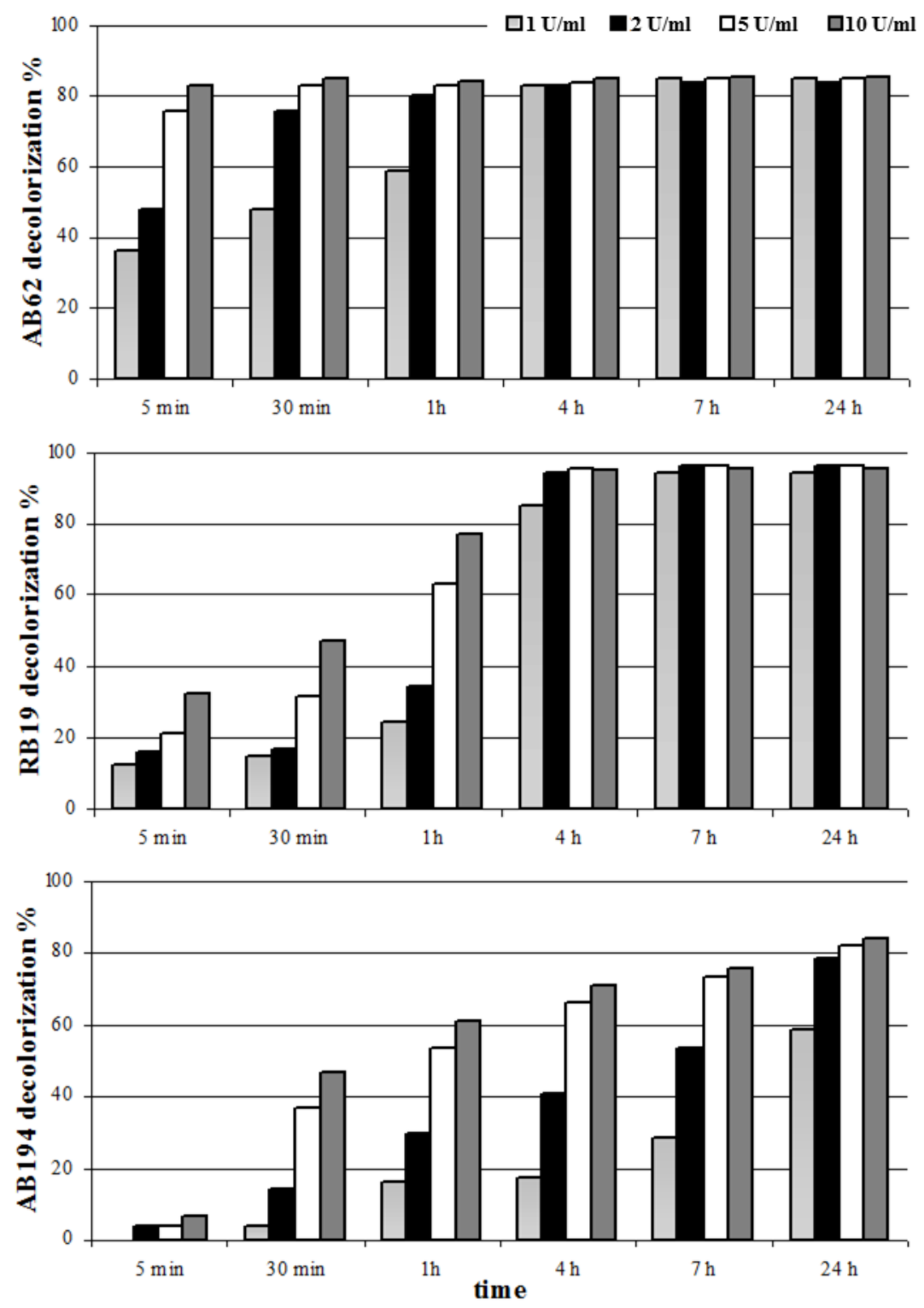

Figure 5. 


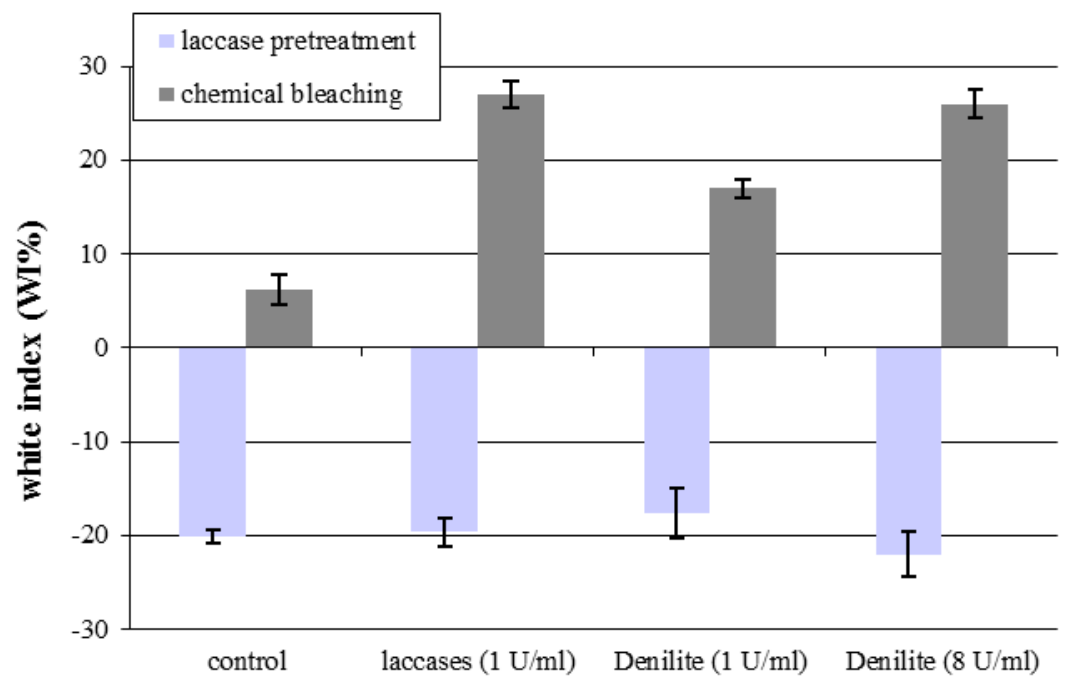

Figure 6. 


\section{List of Figures Legends}

Fig.1 Surface plot of space-time yield $\left(\mathrm{U}^{-1} \mathrm{~d}^{-1}\right)$ : function of $\mathrm{Cu}$ and $\mathrm{C} / \mathrm{N}$ ratio concentrations at the fixed value of RB19 (0.4 mM) (a) and function of $\mathrm{RB} 19$ and $\mathrm{C} / \mathrm{N}$ ratio at the fixed value of $\mathrm{Cu}(1.2 \mathrm{mM})(\mathrm{b})$

Fig.2 Time course of laccase activity $(\square), \mathrm{pH}(\boldsymbol{\Delta})$ and residual glucose concentration percentage (०) after induction with $\mathrm{Cu} 1.2 \mathrm{mM}$ and $\mathrm{RB} 192.0 \mathrm{mM}$

Fig.3 Residual laccase activity towards ABTS, DMP, guaiacol and syringaldazine at different pH values Fig.4 Decolorization time course of AB62, RB19 and AB194 (500 ppm) by 1-10 U/ml laccases

Fig.5 White index (WI\%) of the cotton fibers after the enzymatic pretreatment and after the chemical bleaching by means of $\mathrm{H}_{2} \mathrm{O}_{2}$. In the control, the raw textile fabric was just buffered but no laccases were applied 